\title{
$\nabla$ A Time-Motion Study in the Immunization Clinic of a Tertiary Care Hospital in Odisha
}

\section{IJCRR}

Section: Healthcare

ISI Impact Factor

(2019-20): 1.628

IC Value (2019): 90.81

$\operatorname{SJIF}(2020)=7.893$

(c) (7) (8)

Copyright@IJCRR

\section{Maharana Sabita ${ }^{1}$, Kanyari S Suneeti ${ }^{2}$, Mishra Aparajita ${ }^{3}$}

'Senior Resident, Department of Community Medicine, Kalinga lnstitute of Medical Sciences, Bhubaneswar, Odisha, India; ${ }^{2}$ Assistant Professor, Department of Community Medicine, Kalinga Institute of Medical Sciences, Bhubaneswar, Odisha, India; 3PG student, Department of Community Medicine, Kalinga Institute of Medical Sciences, Bhubaneswar, Odisha, India.

\section{ABSTRACT}

Introduction: A time-motion study helps us to determine the amount of time necessary to perform a specific movement or task. Aims: To determine the activity time at different service delivery points.

Methods: The present observational cross-sectional study was done in the immunization clinic of Kalinga Institute of Medical Sciences (KIMS), Bhubaneswar, Odisha, over 2 months from 01/08/2020 to 30/09/2020. The sample size was 327 . The study population included the mothers/caregivers attending the immunization clinic with their children. Predesigned and pretested schedules were used to record time and other information, while pre-synchronised stopwatches were used to record the total activity time at various stations of the immunization clinic.

Results: The mean total time taken (from entry to exit) for each participant to complete the immunization process was $36.6 \pm 15.7$ minutes. The mean total time was maximum during registration and checking of immunization status, $14.3 \pm 6.2$ minutes. This was followed by the mean time for vaccination proper which was $10.8 \pm 4.5$ minutes. The highest number of beneficiaries visiting the immunization clinic was on Wednesday and the mean total time at all service delivery points was maximum on Wednesday (42.5 \pm 19.8 minutes) between 10 am - 12 pm.

Conclusion: Time management at all levels of the health care system is the need of the hour which has to be addressed. Efficient functioning of the immunization clinic is therefore required to achieve the goal of universal immunization.

Conclusions: In this study, there was a statistically significant correlation between IDA and simple FS.

Keywords: Time motion study, Immunization, Vaccine, Tertiary care hospital, Odisha, Eastern India

\section{INTRODUCTION}

Time is the most valuable thing a man can spend (Theophrastus). A Time Motion study is a business efficiency technique that combines the time study work of Frederick Winslow Taylor (1881 A.D) along with the motion study work of Frank.B. Gilbert and his wife Lillian Gilberth (1885 A.D). This constitutes a major part of scientific management (Taylorism). Time study measures the time taken by an average worker for completion of a task at a normal pace, while motion study is designed to determine the best way of completing a repetitive job. ${ }^{1}$ Time Motion study attempts to track the time records of activities of an individual or group of people, by capturing the time spent on an activity. Thus it is possible to determine the amount of time needed to execute that activity and whether the time is used efficiently. ${ }^{2}$
Historically, both the studies were discussed individually, but today they have become integrated and refined into a widely accepted method applicable for the improvement and upgrading of work systems. This integrated approach is applied for determining schedules and planning of work in the industry as well as service organisations, including banks, schools and hospitals. The objective of the "Time Motion Study" is to determine the normal time taken for a job, by using observers to record the exact amount of time being devoted to each task. Keeping this objective in view, time and motion studies can be effective for performance evaluations as well as used for planning purposes. ${ }^{3}$

The outpatient department (OPD) is considered to be a window to hospital services and a patient's impression of the hospital begins at the OPD. It requires a systematic study of

\section{Corresponding Author:}

Kanyari S Suneeti, Department of Community Medicine, KIMS, Patia, Bhubaneswar, Odisha 751024, India. Mobile: 9778497757; Email: purnima.ssk@gmail.com

ISSN: 2231-2196 (Print)

Received: 07.02 .2021
ISSN: 0975-5241 (Online)

Revised: 15.03 .2021
Accepted: 25.04 .2021 
its services for efficient management and function. Thereby it is necessary that a simple and motion study of an OPD system along with suitable inexpensive interventions can go a long way to improve the efficiency of a hospital. As the name suggests "time-motion study" is concerned mainly with improving the performance by measuring and then minimising the time taken to perform various operations, without compromising the quality of services. Although "Time Motion" studies are time-consuming, they help in the most accurate measurement of structured components. ${ }^{4}$

Immunisation is considered one of the most cost-effective public health interventions, which directly or indirectly prevents the bulk of mortality in under-5 children. ${ }^{5}$ These clinics deal with the most vulnerable and sensitive section of the population, for whom preventive and promotive care is essential. Hence the present study is being carried out in the immunisation clinic of a tertiary care hospital in Odisha, to determine the activity time at different service delivery points in the immunisation clinic.

\section{MATERIALS \& METHODS}

This observational cross-sectional study was carried out in the immunization clinic of Kalinga Institute of Medical Sciences (KIMS), Bhubaneswar, Odisha, over 2 months from $1^{\text {st }}$ August 2020 to $30^{\text {th }}$ September 2020 after getting approval from Institutional Ethics Committee, KIMS bearing ethical clearance number KIIT/KIMS/IEC/353/2020. The study population included the mothers/caregivers attending the immunization clinic with their children. The registration record of the immunization clinic was reviewed for the data of the past year and the average daily registration including both the old and new cases were found to be 30 in number. Every fifth mother/caregiver registering in the immunization clinic on the day of the study was selected by systematic random sampling method. Considering the average number of working days in a month to be 25 , the sample size was calculated to be 300 . The final sample size achieved was 327 . Informed written consent was obtained from each participant included in this study beforehand.

Predesigned and pretested schedules were used to record time and other information and pre-synchronized stopwatches were used to record the total activity time at various stations of the immunization clinic. As the timing of the immunization clinic was from 9 am to $1 \mathrm{pm}$, data collection started at $9 \mathrm{am}$. Time was recorded at the following points:

a) Entry to the immunization clinic

b) Table 1- Immunization registration (History taking, Treatment and record entry) ( Entry time and Exit time) c) Table 2- Nutritional Assessment (Entry time and Exit time)

d) Table 3-Vaccination Proper (Entry time and Exit time)

e) Table 4-Postvaccination Advice (Entry time and Exit time)

f) Exit time

The following activities were carried out in the respective immunization tables.

In immunization Table 1, registrations of old and new cards were done and they were allotted a day specific serial number. The cards were assessed and vaccines scheduled for that day were prescribed. If any mother/caregiver opted for optional vaccines, they were being prescribed and instructed to procure the vaccines from the pharmacy. During rush hours they were made to wait outside the immunization clinic after this step and they were called according to their serial number.

In immunization Table 2, nutritional assessment of the child was carried out by clinical and anthropometric methods. A comparison with previous records was done in the case of old cards and health education was given to the mother/caregiver.

In immunization Table 3, vaccines scheduled for the day were given to the children after verifying their cards again.

In immunization Table 4, post-vaccination advice was given to the mother/caregiver regarding the management of pain and fever after vaccination, nutrition of the child and when to return to the hospital in case any side effect was developed.

The motion of every mother/caregiver selected for the study was followed from the entry till the exit from the immunization clinic in the above-mentioned sequence and time spent in the above-mentioned activity points was recorded.

Statistical analysis was done using software SPSS version 21. Time spent has been expressed as mean and the unit of measurement was minute.

\section{RESULTS}

Out of 327 study subjects most of them belongs to the $0-6$ years age group; of which 254(77.8\%) were infants (below 1year of age) and 164 (50.1\%) were female. 98 participants came for the first time to the immunization clinic while 229 were old cases. The mean total time is taken (from entry to exit) for each participant to complete the immunization process was $36.6 \pm 15.7$ minutes. 
Table 1: Service Delivery time at different activity points

\begin{tabular}{|c|c|c|c|}
\hline Sr No & Activity Points & $\begin{array}{l}\text { Mean } \pm \text { SD time } \\
\quad \text { (in mins) }\end{array}$ & $\%$ of total activity time \\
\hline 1 & $\begin{array}{l}\text { Registration at Immunization clinic and checking } \\
\text { of Immunization status }\end{array}$ & $14 \cdot 3 \pm 6.2$ & $39 \%$ \\
\hline 2 & Nutritional assessment & $5.2 \pm 2.1$ & $14.2 \%$ \\
\hline 3 & Vaccination Proper & $10.8 \pm 4.5$ & $29 \cdot 5 \%$ \\
\hline \multirow[t]{2}{*}{4} & Post Vaccination advice & $6.3 \pm 2.9$ & $17 \cdot 3 \%$ \\
\hline & Total Activity time & $36.6 \pm 15.7$ & 100 \\
\hline
\end{tabular}

Table 1 shows the service delivery time at different activity points. The mean time was maximum during registration, history taking, checking of immunization status and prescription advice i.e14.3 \pm 6.2 minutes which constitutes $39 \%$ of the total activity time. This was followed by the meantime for vaccination proper (preparation and vaccine administration) and post-vaccination advice which constituted $29.5 \%$ and $17.3 \%$ of total activity time.

Table 2: Service Delivery time about the day of visit

\begin{tabular}{|c|c|c|c|c|c|c|}
\hline $\begin{array}{l}\text { No. of Beneficiaries } \\
(\mathrm{N}=327)\end{array}$ & $\begin{array}{c}\text { Monday } \\
71\end{array}$ & $\begin{array}{c}\text { Tuesday } \\
63\end{array}$ & $\begin{array}{c}\text { Wednesday } \\
87\end{array}$ & $\begin{array}{c}\text { Thursday } \\
45\end{array}$ & $\begin{array}{c}\text { Friday } \\
32\end{array}$ & $\begin{array}{c}\text { Saturday } \\
29\end{array}$ \\
\hline \multicolumn{7}{|l|}{ Activity } \\
\hline $\begin{array}{l}\text { Registration at Immunization } \\
\text { clinic and checking of Immuniza- } \\
\text { tion status }\end{array}$ & $16.2 \pm 7.6$ & $15.1 \pm 6.2$ & $17 \cdot 5 \pm 8 \cdot 3$ & $14 \cdot 3 \pm 5 \cdot 2$ & $14.0 \pm 7.1$ & $13.6 \pm 6.4$ \\
\hline Nutritional assessment & $5.4 \pm 2.2$ & $5 \cdot 9 \pm 3.8$ & $6.1 \pm 2.8$ & $5 \cdot 5 \pm 2.6$ & $5 \cdot 3 \pm 2.0$ & $5.2 \pm 2.1$ \\
\hline Vaccination Proper & $11.1 \pm 4 \cdot 3$ & $10.0 \pm 4 \cdot 7$ & $11.9 \pm 5 \cdot 5$ & $9 \cdot 3 \pm 4 \cdot 3$ & $10.5 \pm 4 \cdot 3$ & $9.2 \pm 4 \cdot 5$ \\
\hline Post Vaccination advice & $5 \cdot 9 \pm 2.1$ & $6.8 \pm 3.4$ & $7.0 \pm 3.2$ & $4.2 \pm 2.1$ & $5.4 \pm 1.9$ & $4 \cdot 3 \pm 1.9$ \\
\hline Total Activity time & $38.6 \pm 16.2$ & $37.8 \pm 18.1$ & $42.5 \pm 19.8$ & $33.3 \pm 14.1$ & $35.5 \pm 15 \cdot 3$ & $32.3 \pm 14.9$ \\
\hline
\end{tabular}

Table 2 shows service delivery time on the day of visit. It was found that the highest no. of beneficiaries $(n=87)$ visiting the immunization clinic were on Wednesday. The mean time was maximum in all the service delivery points includ- ing the mean total time between entrances to exit $(42.5 \pm 19.8$ minutes) on Wednesday and was minimum on Saturday $(32.3 \pm 14.9$ minutes). This difference of meantime among the days of the week was statistically significant $(\mathrm{p}<0.001)$.

Table 3: Service delivery time about time of visit

\begin{tabular}{|c|c|c|c|c|}
\hline $\begin{array}{l}\text { No. of Beneficiaries } \\
(\mathbf{N}-327)\end{array}$ & $\begin{array}{c}9-10 \text { am } \\
64\end{array}$ & $\begin{array}{l}10-11 \text { am } \\
112\end{array}$ & $\begin{array}{c}11-12 \text { am } \\
98\end{array}$ & $\begin{array}{l}\text { 12- } 1 \text { pm } \\
53\end{array}$ \\
\hline \multicolumn{5}{|l|}{ Activity } \\
\hline $\begin{array}{l}\text { Registration at Immunization clinic and check- } \\
\text { ing of Immunization status }\end{array}$ & $12.9 \pm 4.2$ & $15 \cdot 3 \pm 4 \cdot 5$ & $14.2 \pm 6.7$ & $12.2 \pm 5.1$ \\
\hline Nutritional assessment & $5.2 \pm 2.4$ & $5.8 \pm 2.1$ & $5.6 \pm 2.5$ & $5 \cdot 5 \pm 1.9$ \\
\hline Vaccination Proper & $10.8 \pm 4.5$ & $11.5 \pm 4.7$ & $11.2 \pm 2.4$ & $9.8 \pm 3 \cdot 5$ \\
\hline Post Vaccination advice & $6.6 \pm 3.1$ & $6.7 \pm 3.3$ & $6.5 \pm 1.6$ & $6.6 \pm 2.8$ \\
\hline Total Activity time & $35 \cdot 5 \pm 14.2$ & $39 \cdot 3 \pm 14.6$ & $37.6 \pm 13.2$ & $34.1 \pm 13 \cdot 3$ \\
\hline
\end{tabular}


Table 3 shows service Delivery time at the time of visit. The total mean time taken for service was more from 10 am to12 pm. The service delivery time was maximum between 1011 am $(39.3 \pm 14.6)$ and minimum between $12-1$ pm $(34.1 \pm$ 13.3). The difference observed between the timing of the visit was found to be statistically significant. $(\mathrm{P}<0.01)$

\begin{tabular}{|c|c|c|}
\hline $\begin{array}{l}\text { Type of Vaccination } \\
\text { given }\end{array}$ & $\begin{array}{l}\text { No. of Ben- } \\
\text { eficiaries }\end{array}$ & $\begin{array}{c}\text { Mean total activity } \\
\text { time } \\
\text { (in minutes) }\end{array}$ \\
\hline $\mathrm{BCG}$ & 86 & $5.2 \pm 3.5$ \\
\hline OPV & 152 & $4.1 \pm 1.8$ \\
\hline Hepatitis B & $5^{2}$ & $7 \cdot 3 \pm 3 \cdot 4$ \\
\hline Pentavalent & 130 & $8.3 \pm 5.3$ \\
\hline Rotavirus vaccine & 122 & $5.5 \pm 1.6$ \\
\hline f- IPV & 85 & $7.1 \pm 3.8$ \\
\hline MMR/MR & 78 & $10.2 \pm 4.1$ \\
\hline JE & 87 & $10.4 \pm 2.9$ \\
\hline $\mathrm{DPT}$ & 25 & $8.5 \pm 3.2$ \\
\hline Vitamin A & 93 & $6.4 \pm 1.7$ \\
\hline Pneumoccocal & 62 & $13.2 \pm 3.5$ \\
\hline Flu & 40 & $12.1 \pm 3.8$ \\
\hline
\end{tabular}

Table 4 shows the total activity time concerning the type of vaccine to be given. Maximum meantime $13.2 \pm 3.5 \mathrm{mins}$ was required for Pneumococcal vaccination and the minimum time $4.1 \pm 1.8$ mins was for Oral Polio vaccine.

\section{DISCUSSION}

Time, motion studies can be effective for performance evaluation, planning purposes, to predict the level of output that can be achieved and to unmask problems and hence create solutions and can also be used for time-cost analysis. The outpatient department serves to be the point of contact between the health care facility and the community. There are varied problems of the OPD's of developing countries which include: long waiting periods, long queues, inefficient, insufficient staff etc. ${ }^{4}$ These problems gets intensified when the OPD deals with pediatric patients such as in immunisation clinics. Different components of work require varying times for the completion of the task. Finding the time required for individual sub-components can thus enable us to take suitable measures to complete the task in lesser time.

In the present study, the maximum time was required for initial OPD registration, history taking, checking of immunisation status and prescription advice, that is, $14.3 \pm 6.2 \mathrm{~min}$, constituting $39 \%$ of the total activity time, which was almost similar to the findings from a study conducted by Deepika et al. being $24.9 \%{ }^{6}$ In the present study, the total time spent by each patient to avail the OPD services was $36.6 \pm 15.7$ minutes, whereas in a study conducted by Rahim et al. it was found that each patient spent an average of 66.64 minutes to avail OPD services. ${ }^{7}$ In studies conducted by Ishwar et al. and Umar et al. the average time spent by each patient was 75.5 minutes and 85 minutes respectively, being higher than the present study. 8,9

In a study from the immunisation clinic of Kolkata, West Bengal, the maximum time required was for vaccination and post-vaccination and the maximum number of beneficiaries and the maximum activity time was on Monday. ${ }^{4}$ In the present study the maximum number of beneficiaries and the maximum time $(42.5 \pm 19.8 \mathrm{~min})$ required for the activity was on Wednesday, owing to a heavy rush on that day due to the availability of government vaccines. This finding was not similar to a study conducted by Manna et al. and Chopade R et al. as well where more time was required on Mondays. ${ }^{10,11}$ The mean time was minimum on Saturday (32.3 $\pm 14.9 \mathrm{~min})$.

In this study, the mean service delivery was maximum between 10-11 am $(39.3 \pm 14.6)$ and minimum between 12-1 pm $(34.1 \pm 13.3)$. A study done by Kumar V et al. found that the service delivery time was at its maximum at the beginning of the day and gradually decreases during subsequent sessions which were similar to our study. Multiple factors could be responsible for this difference observed about the time of visit like total caseload, waiting time and service time in getting various services at the immunization clinic. ${ }^{12}$

In a study conducted by Deepika et al. the maximum meantime was taken for BCG vaccination. ${ }^{6}$ However in the present study, the maximum meantime was required for Pneumococcal vaccination $(13.2 \pm 3.5 \mathrm{~min})$ which may be due to the non-availability of the vaccine in our state immunisation schedule. Therefore, more time is required both for counselling by the health care provider and purchase of vaccine by the beneficiaries. Minimum time was required for Oral Polio Vaccine $(4.1 \pm 1.8 \mathrm{~min})$.

However, such variations need to be studied in depth. Even the factors affecting the waiting time and service time in different tables may be studied separately for further future discussion. Congestion of OPD varies according to the nature of the speciality of the hospital. ${ }^{13}$ A time-motion study of operation theatre time during laparoscopic cholecystectomy by surgery residents observed the need for a change of the current layout of the operating room for time-saving. ${ }^{14}$ Likewise a time-motion study at New Delhi and North India showed that cataract surgical output can be increased in the country if operation theatre time is utilized optimally. ${ }^{15}$ The present study represents one of the very few time, motion studies of immunisation clinics in developing countries and as such provides a useful baseline for future studies. By identifying 
the lacunae and constraints in the system, the quality and efficiency of immunisation services can be improved.

Perhaps we think that this study will help in the initiation of further in-depth analysis of the constraints and lacunae in the implementation of the immunisation program in developing countries and in providing guidelines for the optimal functioning of the system. The present study also has its limitation in itself being an observational study design. The results of the study cannot be generalised since the data was collected from a single immunisation clinic of a private medical college in Eastern India. This study can be done on a wider area and further research can be done for evaluation of the effectiveness of integrating the time and motion model into the existing immunisation program and subsequent remedial steps for optimal functioning of the program.

\section{CONCLUSION}

Time management at all levels of the health care system is the need of the hour which has to be addressed. Efficient functioning of the immunization clinic is therefore required to achieve the goal of universal immunization. This study aims to initiate an effort to study the utilization of time at a single health care unit with the invitation of a much more in-depth analysis of the method of functioning and subsequent remedial steps for optimal functioning of the health care system.

\section{ACKNOWLEDGEMENT}

The authors acknowledge the help of the institute for permitting them to carry out the study. We are also grateful to the researchers and publishers whose articles are referred to in the present article.

Conflict of Interest: The authors declare no conflict of interest.

Funding: No funding received.

\section{Author's contribution:}

$1^{\text {st }}$ author: Concept and design of the study, conducted the study, analysis, interpretation and writing the manuscript.

$2^{\text {nd }}$ author: Concept and design of the study, conducted the study, analysis, interpretation, writing and drafting the manuscript.

$3^{\text {rd }}$ author: Design of the study, conducted the study and writing the manuscript.

\section{REFERENCES}

1. Anand TR, Gupta YP. Rationalization of working of OPD in a hospital: A case study. Health Population, Perspective and Issues. 1983;6:77-94.

2. Abotsi AK. A Time and Motion Study of the Time Burden on Health Workers Administering Expanded Programme of Immunization and Intermittent Preventive Treatment for Infants in the Upper East Region of Ghana. J. Interdiscip. Stud. 2011;4(2):3743,0855- 9724 .

3. Gowler D, Legge K. Writing and the Advent of Scientific Management: The Case of Time and Motion Studies. Scand. J. Manag. $2013 ; 12(1): 41-55$.

4. Chattopadhyay A, Ghosh R, Maji S, Ray TG, Lahiri SK. A time-motion study in the immunization clinic of a tertiary care hospital of Kolkata, West Bengal. Indian J Community Med. 2012;37(1):30-3.

5. WHO, UNICEF, World Bank. State of the world's vaccines and immunization, 3rd ed. Geneva, World Health Organization, 2009.

6. Deepika S, Parande MA, Surwade J, Tapare V, Tambe M, Bhattacharya S. A Time Motion study in the Immunization Clinic of a tertiary care hospital, BJGMC Pune. Indian J Public Health Res Dev. 2017;8(4):892-896.

7. Rahim E, Rahman M, Talukdar AM, Anwar KS. Waiting Time of the Patients at Medical College OPD of Dhaka Medical College Hospital. J Med Sci Res. 2007;08:16-20.

8. Aswar NR, Kale KM, Rewatkar MP. Patients' waiting time and their satisfaction of health care services provided at the outpatient department of Government Medical College, Nanded (Maharashtra, India). Int J Health Sci Res. 2014;4(4):21-27.

9. Oche UIMO, Umar AS. Patient waiting time in a tertiary health institution in Northern Nigeria. J Public Health Epidemiol. 2011;3(2):78-82

10. Manna N, Samsuzzaman M, Das S. A time motion study in the OPD clinic of a rural hospital of West Bengal. IOSR J Dent Med Sci. 2014;13(7):34-7.

11. Chopade RR, Sharma NK, Sundar SM. A time and motion study in the outdoor patient department of the rural health training centre of the tertiary medical college in the Konkan region, India. Int J Community Med Public Health. 2019;6:3242-5.

12. Kumar V, Mangal A, Panesar S, Yadav G, Talwar R, Raut D et al. Operational efficiency of an immunization clinic attached to the rural health training centre in Delhi, India: a time and motion study. Adv Prev Med. 2014;2014:671963.

13. Harshallowalekar, Ravichandran N. Managing the outpatient department waiting time at the rajas eye hospital. IMJ. 2012;4(1):36-46.

14. Geryane MH, Hanna GB, Cuschieri A. Time-motion analysis of operation theatre time use during laparoscopic cholecystectomy by surgical specialist residents. Surg Endosc 2004;18:1597-600.

15. John N, Murthy GV, Vashist P, Gupta SK. Work capacity and surgical output for cataracts in the national capital region of Delhi and neighbouring districts of North India. Indian J Public Health 2008;52:177-84. 